\title{
FLT3-ITD Allelic Burden and Acute Promyelocytic Leukemia Risk Stratification
}

\author{
Andrew Y. Li ${ }^{1}$, Sarah M. Kashanian ${ }^{1}$, Bryan C. Hambley ${ }^{2}$, Kyle Zacholski ${ }^{2}$, Vu H. Duong ${ }^{1,3}$, Firas El Chaer 1,3 ${ }^{\mathbb{D}}$, \\ Noa G. Holtzman 1,3, Ivana Gojo ${ }^{2}$, Jonathan A. Webster ${ }^{2}$, Kelly J. Norsworthy ${ }^{2}$, Bruce Douglas Smith ${ }^{2}$, \\ Amy E. DeZern ${ }^{2}$, Mark J. Levis ${ }^{2}$, Maria R. Baer ${ }^{1,3}$, Farin Kamangar ${ }^{4}$, Gabriel Ghiaur ${ }^{2, *(D)}$ \\ and Ashkan Emadi 1,3,5,*iD
}

1 Department of Medicine, University of Maryland School of Medicine, Baltimore, MD 21201, USA; ali@som.umaryland.edu (A.Y.L.); skashanian@som.umaryland.edu (S.M.K.); vduong@umm.edu (V.H.D.); FE2GH@hscmail.mcc.virginia.edu (F.E.C.); noa.holtzman@nih.gov (N.G.H.); mbaer@umm.edu (M.R.B.)

2 The Sidney Kimmel Comprehensive Cancer Center at Johns Hopkins, Baltimore, MD 21231, USA; bryanhambley@gmail.com (B.C.H.); kyle.zacholski@vcuhealth.org (K.Z.); igojo1@jhmi.edu (I.G.); jwebst17@jhmi.edu (J.A.W.); Kelly.Norsworthy@fda.hhs.gov (K.J.N.); bdsmith@jhmi.edu (B.D.S.); adezern1@jhmi.edu (A.E.D.); levisma@jhmi.edu (M.J.L.)

3 University of Maryland Greenebaum Comprehensive Cancer Center, Baltimore, MD 21201, USA

4 Department of Biology, School of Computer, Mathematical, and Natural Sciences, Morgan State University, Baltimore, MD 21251, USA; farin.kamangar@morgan.edu

5 Department of Pharmacology, University of Maryland School of Medicine, Baltimore, MD 21201, USA

* Correspondence: gghiaur1@jhmi.edu (G.G.); aemadi@umm.edu (A.E.); Tel.: +1-410-502-3183 (G.G.); +1-410-328-6841 (A.E.)

check for updates

Citation: Li, A.Y.; Kashanian, S.M.; Hambley, B.C.; Zacholski, K.; Duong, V.H.; El Chaer, F.; Holtzman, N.G.; Gojo, I.; Webster, J.A.; Norsworthy, K.J.; et al. FLT3-ITD Allelic Burden and Acute Promyelocytic Leukemia Risk Stratification. Biology 2021, 10, 243. https://doi.org/10.3390/ biology10030243

Received: 9 February 2021

Accepted: 18 March 2021

Published: 21 March 2021

Publisher's Note: MDPI stays neutral with regard to jurisdictional claims in published maps and institutional affiliations.

Copyright: (c) 2021 by the authors. Licensee MDPI, Basel, Switzerland. This article is an open access article distributed under the terms and conditions of the Creative Commons Attribution (CC BY) license (https:// creativecommons.org/licenses/by/ $4.0 /)$.
Simple Summary: Around $12-38 \%$ of acute promyelocytic leukemia (APL) patients carry the FLT3ITD mutation, which has been associated with several poor-prognosis indicators such as high white blood cell counts, M3v variant morphology, and the bcr3 isoform. We aimed to retrospectively study the impact of FLT3-ITD mutations in APL patients in regard to clinical features, treatment courses, and outcomes. We demonstrate that Sanz high-risk status APL correlates with high FLT3-ITD allelic burdens, with every $1 \%$ increase in allelic burden correlating with a $0.6 \times 10^{9} / \mathrm{L}$ increase in white blood cell count (WBC). The presence of FLT3-ITD was associated with decreased remission rates and higher 5-year mortality from the time of diagnosis. These findings provide novel revelations regarding the features of FLT3-ITD APL, particularly in regard to allelic burden, that warrant further study.

Abstract: The significance of FLT3-ITD in acute promyelocytic leukemia (APL) is not well-established. We performed a bi-center retrospective study of 138 APL patients, 59 (42.8\%) of whom had FLT3-ITD. APL patients with FLT3-ITD had higher baseline white blood cell counts (WBCs) $(p<0.001)$, higher hemoglobin, $(p=0.03)$, higher aspartate aminotransferase $(p=0.001)$, lower platelets $(p=0.004)$, lower fibrinogen $(p=0.003)$, and higher incidences of disseminated intravascular coagulation $(p=0.005)$, M3v variant morphology $(p<0.001)$, and the bcr3 isoform $(p<0.001)$. FLT3-ITD was associated with inferior post-consolidation complete remission (CR) $(p=0.02)$ and 5-year overall survival (OS) of $79.7 \%$, compared to $94.4 \%$ for FLT3-WT (wild-type) ( $p=0.02$ ). FLT3-ITD was strongly associated with baseline WBCs $\geq 25 \times 10^{9} / \mathrm{L}$ (odds ratio (OR): 54.4; 95\% CI: 10.4-286.1; $p<0.001$ ). High FLT3-ITD allelic burdens correlated with high-risk (HR) Sanz scores and high WBCs, with every $1 \%$ increase in allelic burden corresponding to a $0.6 \times 10^{9} / \mathrm{L}$ increase in WBC. HR APL was associated with a $38.5 \%$ increase in allelic burden compared with low-risk (LR) APL (95\% CI: 19.8-57.2; $p<0.001$ ). Our results provide additional evidence that FLT3-ITD APL is a distinct subtype of APL that warrants further study to delineate potential differences in therapeutic approach.

Keywords: APL; leukemia; FLT3-ITD 


\section{Introduction}

First described by Norwegian hematologist Leif Hillestad in 1957 through a series of three cases, acute promyelocytic leukemia (APL) was aptly named for its predominance of promyelocytes and deadly coagulopathy characterized by "a very rapid fatal course of only a few weeks' duration" [1]. Today with the advent of all-trans retinoic acid (ATRA) and arsenic trioxide (ATO), APL is highly curable if treatment is initiated promptly. APL is classified as the French-American-British (FAB) subtype M3 of acute myeloid leukemia (AML), classically arising from a balanced reciprocal translocation between chromosomes 15 and 17. The fusion between the promyelocytic leukemia (PML) and retinoic acid receptor alpha $(\mathrm{RAR} \alpha)$ genes results in the PML-RAR $\alpha$ rearrangement $\mathrm{t}(15 ; 17)(\mathrm{q} 24 ; \mathrm{q} 21)$, leading to the disruption of the RAR $\alpha$-regulated maturation of myeloid progenitors at the promyelocytic stage [2]. APL comprises less than $10 \%$ of AML, with an estimated $0.01 / 100,000$ incidence in Western countries, affecting men and women equally [3].

FMS-like tyrosine kinase 3 (FLT3) is a proto-oncogene implicated in leukemogenesis. The FLT3 ligand binds to the extracellular FLT3 receptor, inducing homodimerization that potentiates a downstream signaling cascade involved in the regulation of the proliferation, differentiation, and apoptosis of early myeloid and lymphoid progenitor cells. The most common FLT3 aberration is a 3-to->400-base-pair in-frame internal tandem duplication (ITD) mutation within exon 14 that leads to the constitutive activation of the FLT3 receptor and ligand-independent autophosphorylation [4-9]. FLT3-ITD mutations are found in $20-30 \%$ of young adults with AML and are a poor prognostic indicator [9]. Targeted FLT3 inhibitors have been developed such as giltertinib, which was associated with significantly longer overall survival (OS) and higher complete remission (CR) rates compared to those with salvage chemotherapy in relapsed or refractory FLT3-ITD AML [10].

Whereas the importance of FLT3-ITD in AML from prognosis to treatment is well known, its significance in APL is less established. Present in 12-38\% of acute promyelocytic leukemia [5,6], FLT3-ITD has been associated with high white blood cell counts (WBCs), the short PML-RAR $\alpha$ breakpoint cluster region 3 (bcr3) isoform, and microgranular variant M3 (M3v) APL [6-9,11]. The Sanz grouping classifies APL patients as high risk (HR) (WBC $>10$ $\left.\times 10^{9} / \mathrm{L}\right)$, intermediate risk (IR) $\left(\mathrm{WBC} \leq 10 \times 10^{9} / \mathrm{L}\right.$, platelets $\left.\leq 40 \times 10^{9} / \mathrm{L}\right)$, and low risk (LR) $\left(\mathrm{WBC} \leq 10 \times 10^{9} / \mathrm{L}\right.$, platelets $>40 \times 10^{9} / \mathrm{L}$ ) for relapse-free survival (RFS) [12]. Sanz HR APL is associated with FLT3-ITD [8,12]. The clinical outcomes in FLT3-ITD APL remain controversial, and little is known about the impact of ITD insertion length and allelic burden in APL. In this retrospective study, we investigated the significance of FLT3-ITD, insertion length, and allelic burden in APL.

\section{Materials and Methods}

Patients 18 years or older treated at the University of Maryland Medical Center and Johns Hopkins Hospital from January 2000 to May 2020 were included. APL was defined by the cytogenetic and/or molecular confirmation of PML-RAR $\alpha$. FLT3-ITD mutations were targeted at the juxtamembrane region of the FLT3 gene (exons 14-15) via primers, amplified, and identified by fluorescent PCR. The FLT3-ITD allelic burden was estimated as a percent ratio of the area under the curve (AUC) of the variant peak divided by the AUC of the wild-type (WT) peak. The ITD insertion length was determined by subtracting the 328-base-pair PCR product of the FLT3 gene from the base pair size of the variant peak. De-identified patient ages, genders, ethnicities, body mass indices (BMIs), laboratory measurements, Sanz and FLT3-ITD statuses, ITD allelic burdens and insertion lengths, induction chemotherapy regimens, and outcomes were inputted into Microsoft Excel. These data were then transferred to Stata, Version 16.1 (StataCorp, College Station, TX, USA). All the statistical analyses were performed and graphs were made using Stata.

The Chi-square test of independence was run for two categorical variables (e.g., Sanz and FLT3-ITD status). Mean differences between two groups (e.g., FLT3-ITD status) were tested using independent-sample t-tests, and mean differences between three or more groups (e.g., Sanz) were tested using one-way analysis of variance (ANOVA), followed by 
Scheffe tests. Pearson's and Spearman's correlations were used to study the associations of two continuous variables (e.g., allelic burden and WBC). For multiple regression analyses, logistic regression models were used for the associations of independent binary outcomes (e.g., FLT3-ITD status) with independent variables of interest (e.g., Sanz), before and after adjustment for other covariates (e.g., age, gender, and ethnicity). Similarly, linear regression models were used for the association of continuous outcomes (e.g., allelic burden) with independent exposures of interest (e.g., Sanz) before and after adjustment for other covariates. Overall survival (OS) was compared between all groups (FLT3-ITD, FLT3WT, and Sanz HR/IR/LR) using the log-rank test for the equality of survivor functions and graphed using the Kaplan-Meier method. Cox regression models were used to compare survival between groups after adjustment for covariates of interest.

\section{Results}

We identified 138 patients (47 (34.1\%) HR, 54 (39.1\%) IR, and 37 (26.8\%) LR) (Table 1). FLT3-ITD was detected in 59/138 (42.8\%) of the APL patients. There were no significant differences in demographics between any of the groups (age, gender, ethnicity, and BMI). The FLT3-ITD patients were more likely to possess higher WBC $(p<0.001)$, M3v $(p<0.001)$, and bcr3 $(p<0.001)$ characteristics, reported to be associated with worse outcomes in APL $[6-9,11]$. Higher hemoglobin $(p=0.03)$ and aspartate aminotransferase (AST) $(p=0.001)$, lower platelets $(p=0.004)$ and fibrinogen $(p=0.003)$, and a higher incidence of disseminated intravascular coagulation (DIC) $(p=0.005)$ were also noted in our FLT3-ITD cohort, albeit without differences in all-cause bleeding $(p=0.39)$, intracranial hemorrhage $(p=0.80)$, or thrombosis $(p=0.33)$. There were no significant differences noted in the incidences of differentiation syndrome when the cohort was stratified by the presence of FLT3-ITD ( $p=0.29)$, Sanz risk status $(p=0.20)$, and both FLT3-ITD and Sanz risk statuses $(p=0.22)$.

Sanz HR patients were more likely to have FLT3-ITD compared to IR and LR patients (Chi-square test of independence, $\left.X^{2}(2, \mathrm{~N}=138)=37.8, p<0.001\right)$. However, the association between HR status and FLT3-ITD (odds ratio (OR): 13.4; 95\% CI: 4.7-38.3; $p<0.001$ ) disappeared when adjusting for WBCs and platelets (OR: $0.7 ; 95 \%$ CI: $0.1-5.5 ; p=0.80$ ). Sanz LR and IR patients with WBCs $<10 \times 10^{9} / \mathrm{L}$ comprised roughly $66 \%$ of the cohort, leaving the remaining $34 \%$ of HR patients divided evenly into two groups: WBCs of 10-25 $\times 10^{9} / \mathrm{L}$ and $>25 \times 10^{9} /$ L. FLT3-ITD was strongly associated with WBCs $\geq 25 \times 10^{9} / \mathrm{L}$ (OR: 54.4; 95\% CI: 10.4-286.1; $p<0.001)$, similar to the previously reported WBCs $\geq 20 \times 10^{9} / \mathrm{L}$ [7] WBCs of 10-25 $\times 10^{9} / \mathrm{L}$ were, to a lesser degree, also associated with FLT3-ITD (OR: 8.65; 95\% CI: 2.71-27.5; $p<0.001)$. No differences in post-induction complete remission (CR) $(p=0.42)$, post-consolidation CR $(p=0.61)$, induction deaths $(p=0.80)$, and OS $(p=0.33)$ were noted between the Sanz risk groups.

HR APL was associated with an ITD insertion length decrease of 20 base pairs compared to LR APL ( $95 \%$ CI: -40.0 to $-0.23 ; p=0.05$ ); however, this finding was lost when adjusting for platelets $(-13.5 ; 95 \% \mathrm{CI}:-38.2-11.2 ; p=0.3)$. Whereas the ITD insertion length was associated with higher platelet counts ( $\mathrm{rs}=0.39, p=0.003)$, no association was noted between the insertion length and WBC ( $\mathrm{rs}=-0.06, p=0.65)$. A longer ITD insertion length and ITD mutant/wildtype ratio greater than $0.5-0.66$ have been associated with shorter RFS, and OS in APL [9-14]. No correlation between the insertion length and OS was noted in this study $(p=0.38)$. 
Table 1. Baseline demographic and clinical data of 138-patient acute promyelocytic leukemia (APL) cohort differentiated by presence of FLT3-ITD and Sanz risk status.

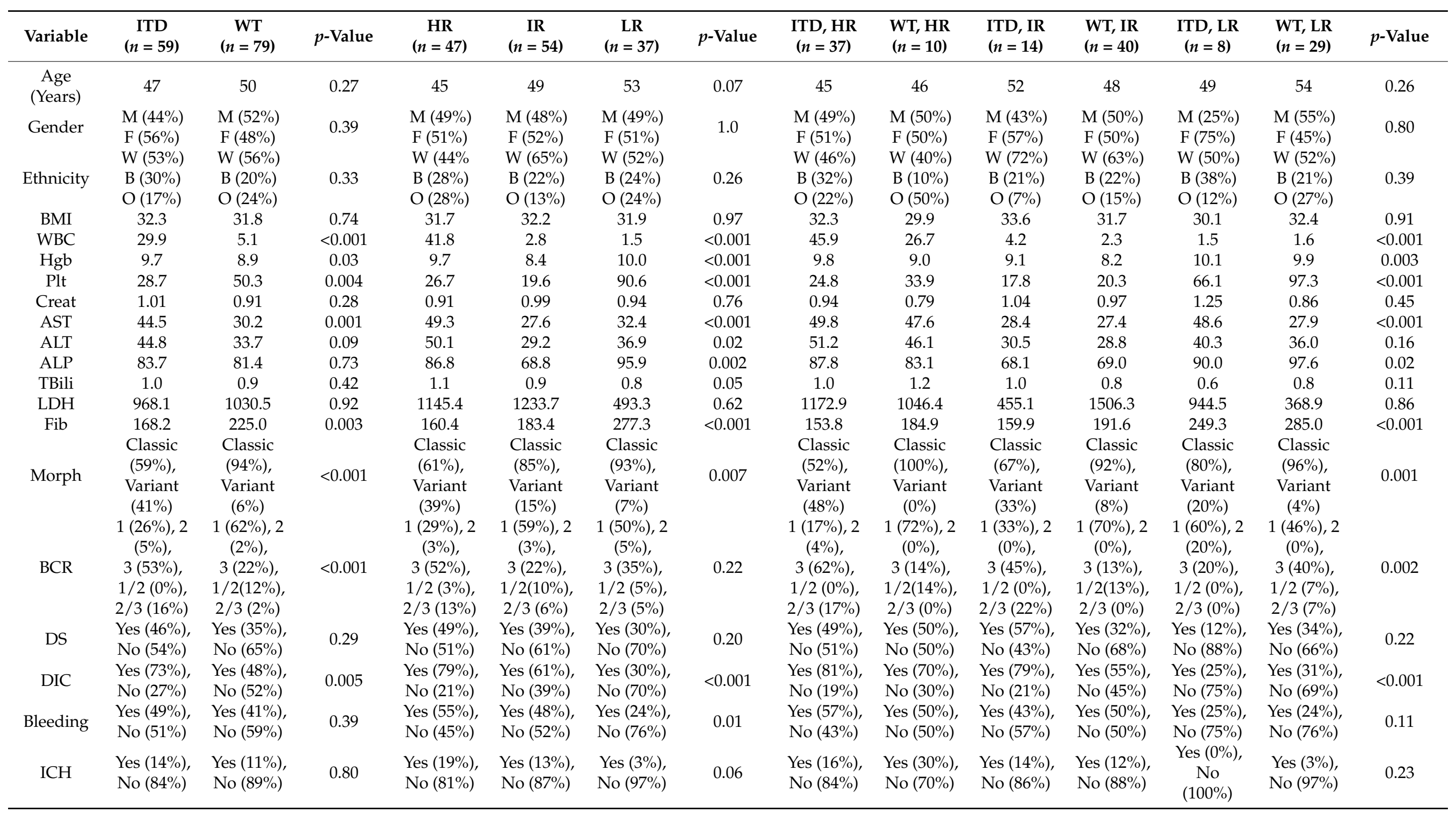


Table 1. Cont.

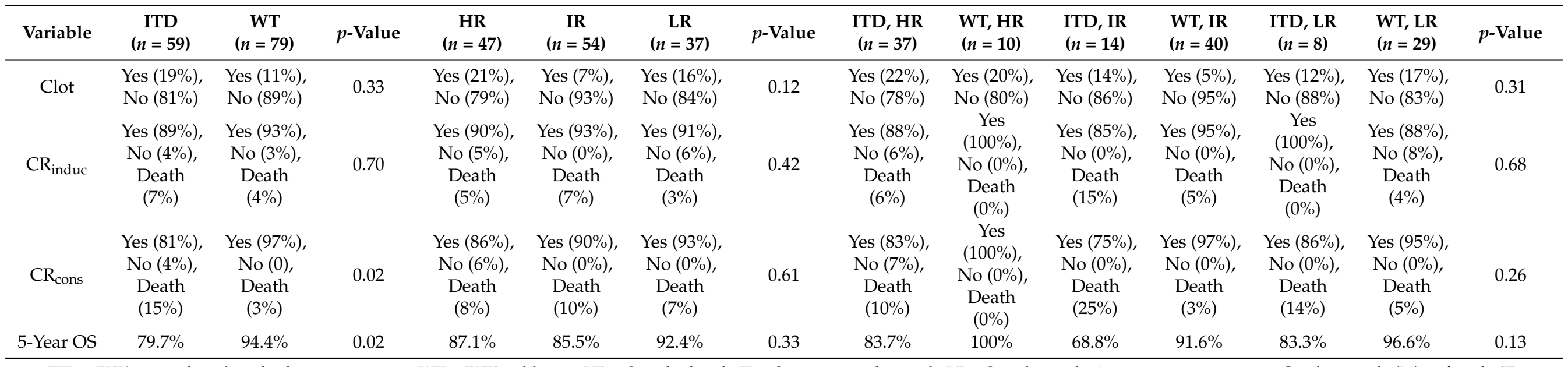

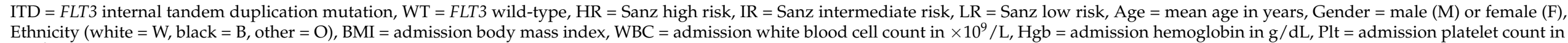

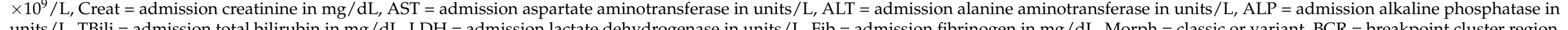

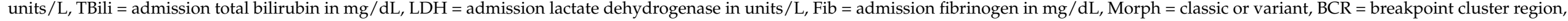

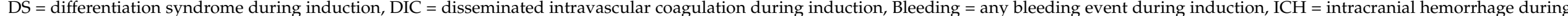

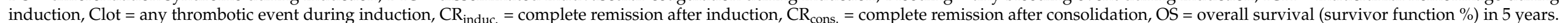


The Sanz risk status significantly correlated with allelic burden according to oneway ANOVA $(\mathrm{F}(2,30)=12.1, p<0.0001)$. According to post hoc Scheffe tests, the allelic burden differed between HR/IR $(p=0.007)$ and HR/LR $(p=0.001)$, but not in IR/LR $(p=0.32)$. These findings persisted when adjusting for center, age, gender, ethnicity, WBC, and platelets via linear regression. HR APL was associated with a $38.5 \%$ increased allelic burden compared with LR APL (95\% CI: 19.8-57.2; $p<0.001)$. According to Spearman's Rho, the FLT3-ITD allelic burden was associated with higher WBCs ( $\mathrm{rs}=0.49, p=0.03$ ). For every $1 \%$ increase in allelic burden, the WBC increased by $0.6 \times 10^{9} / \mathrm{L}$. The relationship between the FLT3-ITD allelic burden and WBC can be visualized in Figure 1. Of note, the majority of the reported allelic ratios (33/59 patients) were from those seen after 2012. There was no significant relationship between the FLT3-ITD allelic burden and OS $(p=0.97)$.

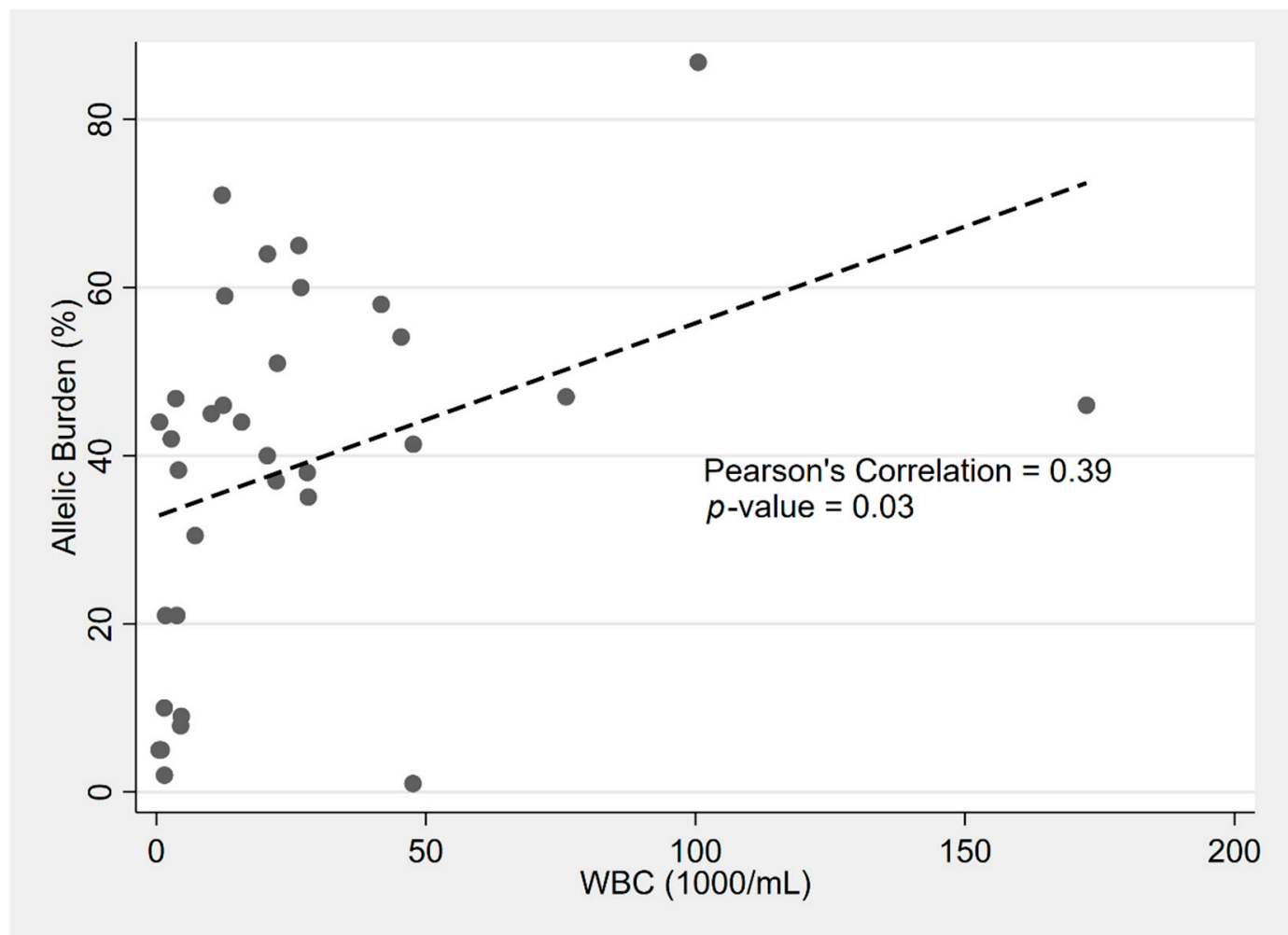

Figure 1. Distribution of FLT3-ITD allelic burden (\%) and associated WBC count $\left(\times 10^{9} / \mathrm{L}\right)$ at diagnosis per patient in FLT3-ITD APL.

While studies have reported a higher incidence of induction death and inferior CR rates, OS, and RFS in FLT3-ITD APL [6,9-11,15,16], we report no significant differences in the CR duration after induction $(p=0.70)$ or death during induction $(p=0.13)$. We found shorter post-consolidation CR durations $(p=0.02)$ and OS $(p=0.02)$ in FLT3-ITD APL (Figure 2). The 5-year OS for patients with FLT3-ITD was 79.7\% compared to $94.4 \%$ for FLT3 wild-type patients. FLT3-ITD was associated with a higher mortality risk, with a hazard ratioof 3.25 (95\% CI: 1.14-9.25; $p=0.027)$. Other studies reported no association between FLT3-ITD and CR/RFS/OS/early death in APL [7,8,11,17-20]. The variability of the outcomes may be attributed to the small cohort size, differences in inclusion criteria, varying treatment protocols, and adherence to follow-up.

Pre-arsenic trioxide (ATO) studies showed reduced OS and increased relapse rates with FLT3-ITD $[9,15,21]$ in APL, whereas post-ATO studies demonstrated no prognostic significance of FLT3-ITD [17-20], suggesting the effect of FLT3-ITD may be mitigated with ATO. Our cohort consisted of 26 FLT3-ITD patients treated with ATO, compared to 32 without ATO, and 41 FLT3-WT patients treated with ATO, compared to 37 without (two patients with unclear induction regimens). When mutually adjusting for FLT3-ITD 
status, the ATO-containing regimens were not associated with improved OS, with a hazard ratio $(95 \% \mathrm{CI})$ of $1.13(0.41-3.16)$. When stratified by the ATO versus non-ATO regimens, FLT3-ITD was associated with increased mortality in both groups. The hazard ratio (95\% CI) was 4.78 (1.01-22.6) for the non-ATO regimens and 3.17 (0.58-17.3) for the ATO-containing regimens $(p$-value for interaction $=0.46)$, suggesting no evidence for the impact of ATOcontaining regimens on the prognostic significance of FLT3-ITD in this study. However, the study sample size was modest, making the power relatively low for detecting effect modification. The number of patients treated with gemtuzumab ozogamicin was too small $(n=4)$ to perform statistical analysis on outcomes.
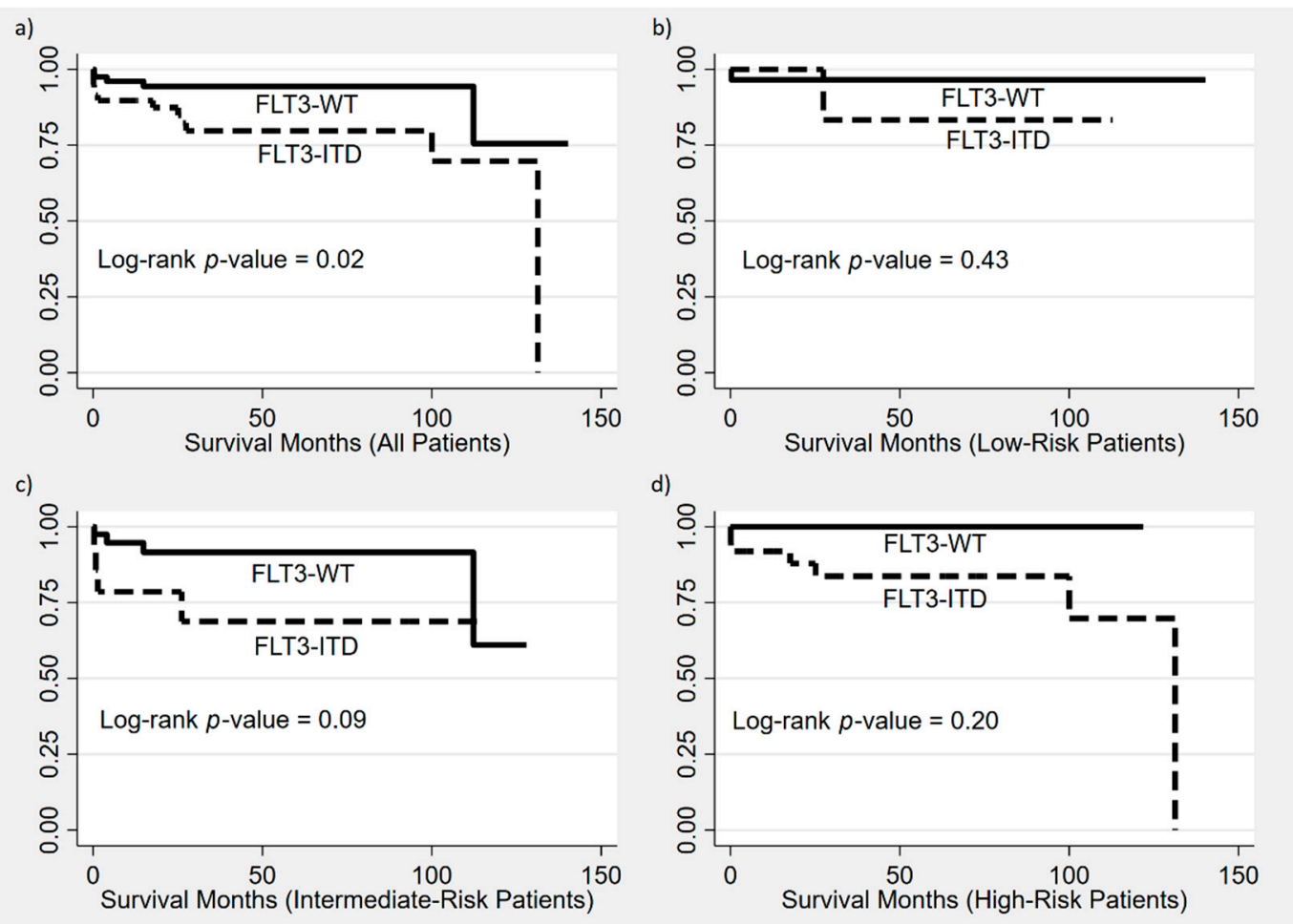

Figure 2. Kaplan-Meier survival curves comparing OS between (a) all patients: FLT3-ITD vs. FLT3-WT, (b) FLT3-ITD/Sanz LR vs. FLT3-WT/Sanz LR, (c) FLT3-ITD/Sanz IR vs. FLT3-WT/Sanz IR, and (d) FLT3-ITD/Sanz HR vs. FLT3-WT/Sanz HR.

\section{Discussion}

APL therapy differs in Sanz HR versus IR/LR groups, and risk-stratifying APL is important for optimizing outcomes. Genes impacting differentiation are downregulated and genes involved in cellular adhesion, invasiveness, and metastasis are upregulated in FLT3-ITD APL [16]. Given the associations of FLT3-ITD with poor prognostic features and outcomes, FLT3-ITD APL has been proposed to be a distinct subtype of APL [7,9]. The high WBCs, M3v, and bcr3 reported in this study have been well-established in FLT3-ITD APL, whereas the shorter post-consolidation CR duration and OS found here are less well-established.

We found a strong correlation between FLT3-ITD and leukocytosis in APL, suggesting a WBC cutoff of $\geq 25 \times 10^{9} / \mathrm{L}$ as an indicator for considering testing for FLT3-ITD in APL. The well-known association between leukocytosis and FLT3-ITD in APL is further expanded upon in this study by the novel revelation of the WBC's relationship with the ITD allelic burden, with every $1 \%$ increase in allelic burden equating to a $0.6 \times 10^{9} / \mathrm{L}$ increase in WBC. Interestingly, the allelic burden was not found to be associated with OS. 


\section{Conclusions}

Taken together, these results support the importance of additional study of the significance of the FLT3-ITD mutation and ITD allelic burden in APL. More data are required to determine the utility of incorporating FLT3-ITD into risk-adapted treatment algorithms and molecular monitoring. The absence of routine testing for FLT3-ITD in APL, the lack of international standardized FLT3-ITD assays, and the rarity of the disease pose limitations for studies of FLT3-ITD APL [6,13].

Author Contributions: Conceptualization, G.G. and A.E.; methodology, F.K., G.G., and A.E.; formal analysis, A.Y.L., F.K., and A.E.; data collection, A.Y.L., S.M.K., B.C.H., K.Z., and F.E.C.; writingoriginal draft preparation, A.Y.L.; writing—review and editing, A.Y.L., S.M.K., B.C.H., K.Z., V.H.D., F.E.C., N.G.H., I.G., J.A.W., K.J.N., B.D.S., A.E.D., M.J.L., M.R.B., F.K., G.G., and A.E.; funding acquisition, G.G. and A.E. All authors have read and agreed to the published version of the manuscript.

Funding: This research was partially funded by the University of Maryland Greenebaum Comprehensive Cancer Center Support Grant, grant number P30CA134274; the NHLBI, grant numbers K08HL127269 and R03HL145226; the NCI, grant number P01CA225618; and the State of Maryland's Cigarette Restitution Funds.

Institutional Review Board Statement: The study was conducted according to the guidelines of the Declaration of Helsinki, and approved by the Institutional Review Boards of the University of Maryland Greenebaum Comprehensive Cancer Institute (Protocol No. 1306GCC, approved 4/2/2020) and Johns Hopkins Sidney Kimmel Comprehensive Cancer Center (Protocol No. NA_00028682/CIR00057353, approved 3/22/2020).

Informed Consent Statement: Patient consent was waived due to the retrospective nature of the study and inclusion of only de-identified patient information in the study.

Data Availability Statement: The data presented in this study are available on request from the corresponding author. The data are not publicly available due to the protection of the de-identified patient information.

Acknowledgments: We acknowledge our patients from the University of Maryland Greenebaum Comprehensive Cancer Center and Johns Hopkins Sidney Kimmel Comprehensive Cancer Center for participating in this study.

Conflicts of Interest: The authors declare no conflict of interest. The funders had no role in the design of the study; in the collection, analyses, or interpretation of data; in the writing of the manuscript; or in the decision to publish the results.

$\begin{array}{ll}\text { Abbreviations } \\ \text { ALP } & \text { alkaline phosphatase } \\ \text { ALT } & \text { alanine aminotransferase } \\ \text { AML } & \text { acute myeloid leukemia } \\ \text { ANOVA } & \text { analysis of variance } \\ \text { APL } & \text { acute promyelocytic leukemia } \\ \text { AST } & \text { aspartate aminotransferase } \\ \text { ATO } & \text { arsenic trioxide } \\ \text { ATRA } & \text { all-trans retinoic acid } \\ \text { AUC } & \text { area under the curve } \\ \text { bcr3 } & \text { breakpoint cluster region } 3 \\ \text { BMI } & \text { body mass index } \\ \text { CR } & \text { complete remission } \\ \text { DIC } & \text { disseminated intravascular coagulation } \\ \text { DS } & \text { differentiation syndrome } \\ \text { FAB } & \text { French-American-British } \\ \text { Fib } & \text { fibrinogen } \\ \text { Hgb } & \text { hemoglobin } \\ \text { HR } & \text { Sanz high risk } \\ \text { ICH } & \text { intracranial hemorrhage }\end{array}$




$\begin{array}{ll}\text { FLT3-ITD } & \text { fms-like tyrosine kinase 3 internal tandem duplication } \\ \text { IR } & \text { Sanz intermediate risk } \\ \text { LDH } & \text { lactate dehydrogenase } \\ \text { LR } & \text { Sanz low risk } \\ \text { M3v } & \text { microgranular variant M3 } \\ \text { Morph } & \text { morphology } \\ \text { OS } & \text { overall survival } \\ \text { PCR } & \text { polymerase chain reaction } \\ \text { Plt } & \text { platelet } \\ \text { PML-RARa } & \text { promyelocytic leukemia retinoic receptor alpha } \\ \text { RFS } & \text { relapse free survival } \\ \text { TBili } & \text { total bilirubin } \\ \text { WBC } & \text { white blood cell } \\ \text { WT } & \text { wild-type }\end{array}$

\section{References}

1. Hillestad, L.K. Acute Promyelocytc Leukemia. Acta Med. Scand. 2009, 159, 189-194. [CrossRef]

2. Thomas, X. Acute Promyelocytic Leukemia: A History over 60 Years-From the Most Malignant to the most Curable Form of Acute Leukemia. Oncol. Ther. 2019, 7, 33-65. [CrossRef]

3. Matasar, M.J.; Ritchie, E.K.; Consedine, N.; Magai, C.; Neugut, A.I. Incidence rates of acute promyelocytic leukemia among Hispanics, blacks, Asians, and non-Hispanic whites in the United States. Eur. J. Cancer Prev. 2006, 15, 367-370. [CrossRef]

4. Parcells, B.W.; Ikeda, A.K.; Simms-Waldrip, T.; Moore, T.B.; Sakamoto, K.M. FMS-Like Tyrosine Kinase 3 in Normal Hematopoiesis and Acute Myeloid Leukemia. StemCells 2006, 24, 1174-1184. [CrossRef] [PubMed]

5. Papaemmanuil, E.; Gerstung, M.; Bullinger, L.; Gaidzik, V.I.; Paschka, P.; Roberts, N.D.; Potter, N.E.; Heuser, M.; Thol, F.; Bolli, N.; et al. Genomic Classification and Prognosis in Acute Myeloid Leukemia. N. Engl. J. Med. 2016, 374, 2209-2221. [CrossRef] [PubMed]

6. Beitinjaneh, A.; Jang, S.; Roukoz, H.; Majhail, N.S. Prognostic significance of FLT3 internal tandem duplication and tyrosine kinase domain mutations in acute promyelocytic leukemia: A systematic review. Leuk. Res. 2010, 34, 831-836. [CrossRef] [PubMed]

7. Melo, C.P.S.; Campos, C.B.; Dutra, Á.P.; Neto, J.C.A.; Fenelon, A.J.S.; Neto, A.H.; Carbone, E.K.; Pianovski, M.A.D.; Ferreira, A.C.D.S.; Assumpcão, J.G. Correlation between FLT3-ITD status and clinical, cellular and molecular profiles in promyelocytic acute leukemias. Leuk. Res. 2015, 39, 131-137. [CrossRef]

8. Callens, C.; Chevret, S.; Cayuela, J.-M.; Cassinat, B.; Raffoux, E.; De Botton, S.; Thomas, X.; Guerci, A.; Fegueux, N.; Pigneux, A.; et al. Prognostic implication of FLT3 and Ras gene mutations in patients with acute promyelocytic leukemia (APL): A retrospective study from the European APL Group. Leukemia 2005, 19, 1153-1160. [CrossRef] [PubMed]

9. Breccia, M.; Loglisci, G.; Loglisci, M.G.; Ricci, R.; Diverio, D.; Latagliata, R.; Foà, R.; Lo-Coco, F. FLT3-ITD confers poor prognosis in patients with acute promyelocytic leukemia treated with AIDA protocols: Long-term follow-up analysis. Haematologica 2013, 98, e161-e163. [CrossRef]

10. Perl, A.E.; Martinelli, G.; Cortes, J.E.; Neubauer, A.; Berman, E.; Paolini, S.; Montesinos, P.; Baer, M.R.; Larson, R.A.; Ustun, C.; et al. Gilteritinib or Chemotherapy for Relapsed or Refractory FLT3-Mutated AML. N. Engl. J. Med. 2019, 381, 1728-1740. [CrossRef]

11. Lucena-Araujo, A.R.; Kim, H.T.; Jacomo, R.H.; Melo, R.A.; Bittencourt, R.; Pasquini, R.; Pagnano, K.; Fagundes, E.M.; Chauffaille, M.D.L.; Chiattone, C.S.; et al. Internal tandem duplication of the FLT3 gene confers poor overall survival in patients with acute promyelocytic leukemia treated with all-trans retinoic acid and anthracycline-based chemotherapy: An International Consortium on Acute Promyelocytic Leukemia study. Ann. Hematol. 2014, 93, 2001-2010. [CrossRef] [PubMed]

12. Sanz, M.A.; Lo Coco, F.; Martín, G.; Avvisati, G.; Rayón, C.; Barbui, T.; Díaz-Mediavilla, J.; Fioritoni, G.; González, J.D.; Liso, V.; et al. Definition of relapse risk and role of nonanthracycline drugs for consolidation in patients with acute promyelocytic leukemia: A joint study of the PETHEMA and GIMEMA cooper-ative groups. Blood 2000, 96, 1247-1253. [CrossRef]

13. Chillón, M.D.C.; Santamaría, C.; García-Sanz, R.; Balanzategui, A.; Eugenia, S.M.; Alcoceba, M.; Marín, L.; Caballero, M.D.; Vidriales, M.B.; Ramos, F.; et al. Long FLT3 internal tandem duplications and reduced PML-RAR expression at diagnosis characterize a high-risk subgroup of acute promyelocytic leukemia patients. Haematologica 2010, 95, 745-751. [CrossRef]

14. Schnittger, S.; Bacher, U.; Haferlach, C.; Kern, W.; Alpermann, T.; Haferlach, T. Clinical impact of FLT3 mutation load in acute promyelocytic leukemia with $\mathrm{t}(15 ; 17) /$ PML-RARA. Haematologica 2011, 96, 1799-1807. [CrossRef]

15. Kuchenbauer, F.; Schoch, C.; Kern, W.; Hiddemann, W.; Haferlach, T.; Schnittger, S. Impact of FLT3 mutations and promyelocytic leukaemia-breakpoint on clinical characteristics and prognosis in acute promyelocytic leukaemia. Br. J. Haematol. 2005, 130, 196-202. [CrossRef] [PubMed]

16. Gill, H.S.; Yim, R.; Kumana, C.R.; Tse, E.; Kwong, Y. Oral arsenic trioxide, all- trans retinoic acid, and ascorbic acid maintenance after first complete remission in acute promyelocytic leukemia: Long-term results and unique prognostic indicators. Cancer 2020, 126, 3244-3254. [CrossRef] [PubMed] 
17. Lou, Y.; Ma, Y.; Suo, S.; Ni, W.; Wang, Y.; Pan, H.; Tong, H.; Qian, W.; Meng, H.; Mai, W.; et al. Prognostic factors of patients with newly diagnosed acute promyelocytic leukemia treated with arsenic trioxide-based frontline therapy. Leuk. Res. 2015, 39, 938-944. [CrossRef] [PubMed]

18. Shen, Y.; Fu, Y.-K.; Zhu, Y.-M.; Lou, Y.-J.; Gu, Z.-H.; Shi, J.-Y.; Chen, B.; Chen, C.; Zhu, H.-M.; Hu, J.; et al. Mutations of Epigenetic Modifier Genes as a Poor Prognostic Factor in Acute Promyelocytic Leukemia Under Treatment With All-Trans Retinoic Acid and Arsenic Trioxide. EBioMedicine 2015, 2, 563-571. [CrossRef]

19. Hu, J.; Liu, Y.-F.; Wu, C.-F.; Xu, F.; Shen, Z.-X.; Zhu, Y.-M.; Li, J.-M.; Tang, W.; Zhao, W.-L.; Wu, W.; et al. Long-term efficacy and safety of all-trans retinoic acid/arsenic trioxide-based therapy in newly diagnosed acute promyelocytic leukemia. Proc. Natl. Acad. Sci. USA 2009, 106, 3342-3347. [CrossRef] [PubMed]

20. Iland, H.J.; Bradstock, K.; Supple, S.G.; Catalano, A.; Collins, M.; Hertzberg, M.; Browett, P.; Grigg, A.; Firkin, F.; Hugman, A.; et al. All-trans-retinoic acid, idarubicin, and IV arsenic trioxide as initial therapy in acute promyelocytic leukemia (APML4). Blood 2012, 120, 1570-1580. [CrossRef]

21. Hong, S.-D.; Kim, Y.-K.; Kim, H.-N.; Lee, S.R.; Ahn, J.-S.; Yang, D.-H.; Lee, J.-J.; Lee, I.-K.; Shin, M.-G.; Kim, H.-J. Treatment outcome of all-transretinoic acid/anthracycline combination chemotherapy and the prognostic impact of FLT3/ITD mutation in acute promyelocytic leukemia patients. Korean J. Hematol. 2011, 46, 24-30. [CrossRef] [PubMed] 